\title{
Noncontact measurement of high-temperature surface tension and viscosity of bulk metallic glass-forming alloys using the drop oscillation technique
}

\author{
S. Mukherjee, ${ }^{\text {a) }}$ W. L. Johnson, and W. K. Rhim \\ Division of Engineering and Applied Science, California Institute of Technology, \\ Pasadena, California 91125
}

(Received 4 August 2004; accepted 3 November 2004; published online 28 December 2004)

\begin{abstract}
High-temperature surface tension and viscosities for five bulk metallic glass-forming alloys with widely different glass-forming abilities are measured. The measurements are carried out in a high-vacuum electrostatic levitator using the drop oscillation technique. The surface tension follows proportional mathematical addition of pure components' surface tension except when some of the constituent elements have much lower surface tension. In such cases, there is surface segregation of the low surface tension elements. These alloys are found to have orders of magnitude higher viscosity at their melting points compared to the constituent metals. Among the bulk glass-forming alloys, the better glass former has a higher melting-temperature viscosity, which demonstrates that high-temperature viscosity has a pronounced influence on glass-forming ability. Correlations between surface tension and viscosity are also investigated. (C) 2005 American Institute of Physics.
\end{abstract} [DOI: $10.1063 / 1.1844596]$

In recent years, several metallic alloys have been discovered, typically close to eutectic compositions, which can be cast in bulk amorphous form even with cooling rates as low as $1 \mathrm{~K} / \mathrm{s} .{ }^{1-4}$ Their unique mechanical properties such as high strength, elastic strain limit, and high fatigue resistance make them interesting as engineering materials. ${ }^{3-5}$ It is of great interest to investigate the role of thermophysical properties of these alloys in determining their glass-forming behavior both from the scientific point of view as well as industrial processes like casting and composite infiltration. Surface tension and viscosity of liquids are two important thermophysical properties which determine their surface and bulk characteristics, respectively. Viscosity is a kinetic parameter that determines the nucleation and growth rates of crystals in the undercooled liquid, while knowledge of surface tension of alloys is vital for studying surface segregation effects and the extent of Marangoni flow. ${ }^{6}$ Although surface tension and viscosity data for pure metals are available in literature, ${ }^{7}$ they are scarce for binary systems and in the case of complex glass-forming alloys a nearly complete lack of data is evident. Data are lacking especially at high temperatures because these glass-forming systems consist of highly reactive elements such as $\mathrm{Ni}, \mathrm{Ti}$, and $\mathrm{Zr}$, which limit the applicability of conventional methods ${ }^{7}$ to measure surface tension and viscosity.

Containerless measurement techniques for surface tension and viscosity are advantageous over conventional methods because they isolate the samples from container walls thereby preventing any chemical reaction. Particularly, the drop oscillation technique used in a high-vacuum electrostatic levitator (ESL) has numerous advantages over other levitation methods: (i) the sample surface is protected because of high vacuum environment, (ii) both the surface tension and viscosity can be obtained from a single transient signal thereby eliminating uncertainties introduced from dif-

\footnotetext{
${ }^{\text {a) }}$ Author to whom correspondence should be addressed; electronic mail:
} sundeep@caltech.edu ferent measurement techniques, and (iii) a single axisymmetric mode can be excited in an almost spherical sample thereby making the data analysis unambiguous.

A number of phenomenological models have been proposed to estimate the surface tension and viscosity for liquid metals from other easily measurable thermophysical properties and reasonable agreement has been found with experiments. ${ }^{7}$ These models have been used to estimate the surface tension and viscosities of alloys where they could not be measured directly, ${ }^{8}$ without testing the validity of extending them to multicomponent systems. These estimates for multicomponent systems may be misleading and this necessitates the experimental determination of reliable viscosity and surface tension data for alloys.

In this letter, we report the high temperature surface tension and viscosities for five different bulk metallic glassforming alloys: $\mathrm{Zr}_{41.2} \mathrm{Ti}_{13.8} \mathrm{Cu}_{12.5} \mathrm{Ni}_{10} \mathrm{Be}_{22.5}$ (Vit1), $\mathrm{Zr}_{57} \mathrm{Cu}_{15.4} \mathrm{Ni}_{12.6} \mathrm{Al}_{10} \mathrm{Nb}_{5}$ (Vit106), $\mathrm{Zr}_{55} \mathrm{Al}_{22.5} \mathrm{Co}_{22.5}$ (ZrAlCo), $\mathrm{Ni}_{60} \mathrm{Nb}_{34.8} \mathrm{Sn}_{5.2}(\mathrm{NiNbSn})$, and the binary eutectic alloy, $\mathrm{Ni}_{59.5} \mathrm{Nb}_{40.5}(\mathrm{NiNb})$. These five alloys were chosen because they have a wide range of glass-forming ability with critical cooling rates for vitrification varying over two orders of magnitude. The measurements were made using the drop oscillation technique in a high vacuum electrostatic levitator (ESL) to avoid heterogeneous influences of containers. The surface tension and viscosity for these bulk metallic glassforming alloys are compared with those of pure metals. Correlations between surface tension and viscosity are also investigated.

The alloys were prepared from high purity starting materials in an arc melter. The glass transition temperatures $\left(T_{g}\right)$ and the liquidus temperatures $\left(T_{L}\right)$ were obtained using a differential scanning calorimeter at a heating rate of $0.33 \mathrm{~K} \mathrm{~s}^{-1}$. The $T_{g}$ and $T_{L}$ values for all five alloys investigated in this study are listed in Table I. Also listed in Table I are the critical cooling rates for vitrification of these alloys, Vit1 being the best and $\mathrm{NiNb}$ being the poorest glass former. The critical cooling rates for Vit1, Vit106, and ZrAlCo were 
TABLE I. Characteristic temperatures and the critical cooling rates for glass formation.

\begin{tabular}{cccc}
\hline \hline BMG & $T_{g}(\mathrm{~K})$ & $T_{L}(\mathrm{~K})$ & Critical cooling rate $\left(\mathrm{K} \mathrm{s}^{-1}\right)$ \\
\hline Vit1 & 620 & 993 & 2 \\
Vit106 & 682 & 1115 & 10 \\
ZrAlCo & 753 & 1323 & 17 \\
NiNbSn & 885 & 1363 & 110 \\
NiNb & 900 & 1448 & 250 \\
\hline \hline
\end{tabular}

measured from their respective time-temperaturetransformation curves, ${ }^{9,10}$ while those of $\mathrm{NiNbSn}$ and $\mathrm{NiNb}$ were estimated from critical casting thickness to form fully amorphous plates. ${ }^{11,12}$ Samples were levitated in the ESL and melted using a high power continuous wave Nd-YAG laser operating at $1.064 \mu \mathrm{m}$. The temperature was measured remotely using a two-color pyrometer with a nominal sensitivity range of $650-1600 \mathrm{~K}$. For surface tension and viscosity measurements, the resonant oscillation of the molten drop was induced by an ac electric field while holding the sample at a fixed temperature. ${ }^{13}$ The surface tension $(\sigma)$ for an isolated liquid drop undergoing small amplitude axisymmetric oscillations with the mode $n=2$, is given by ${ }^{14}$

$$
\omega^{2}=\frac{8 \sigma}{\rho r^{3}},
$$

where $\omega$ is the resonant oscillation frequency, $\rho$ is the density, and $r$ is the radius of the spherical drop. This value of surface tension was corrected to take into account the sample surface charge and the nonsphericity in sample shape. Viscosity $(\eta)$ of the liquid drop was calculated from the decay time constant $(\tau)$ of free oscillation that followed the excitation pulse as: ${ }^{13,15}$

$$
\eta=\frac{\rho r^{2}}{5 \tau} .
$$

Detailed descriptions of the surface tension and viscosity measurement techniques are given elsewhere. ${ }^{13} \mathrm{~A}$ detailed description of the ESL facility itself is given in an earlier publication. $^{16}$

The surface tension for the alloys investigated in this study are shown in Fig. 1. Except for the NiNb binary alloy,

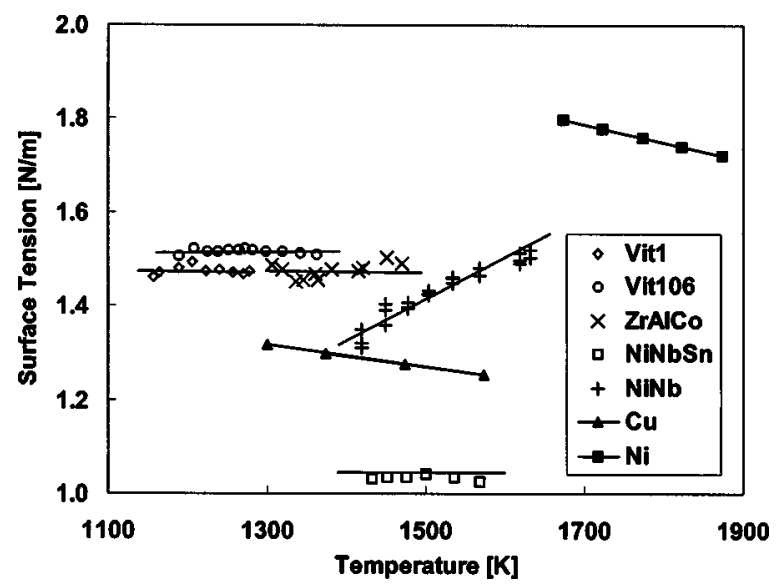

FIG. 1. Surface tension for the alloys investigated in this study. The surface tension for the pure metals $\mathrm{Ni}$ and $\mathrm{Cu}$ (obtained from Ref. 7) is also indicated.

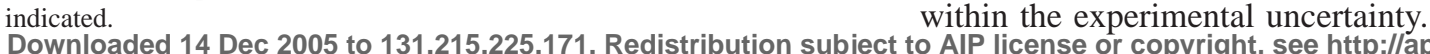

TABLE II. Experimental surface tension values at the melting temperature and the surface tension obtained by rule of mixtures of the constituent pure metals (obtained from Ref. 7).

\begin{tabular}{cccc}
\hline \hline BMG & $\begin{array}{c}\sigma_{m}\left[\mathrm{~N} \mathrm{~m}^{-1}\right] \\
\text { (Experiment) }\end{array}$ & $\begin{array}{c}\sigma_{m}\left[\mathrm{~N} \mathrm{~m}^{-1}\right] \\
\text { (Rule of mixtures) }\end{array}$ & \% deviation \\
\hline Vit1 & 1.47 & 1.49 & -1.35 \\
Vit106 & 1.51 & 1.45 & +4.05 \\
ZrAlCo & 1.47 & 1.44 & +2.06 \\
$\mathrm{NiNbSn}$ & 1.04 & 1.76 & -51.43 \\
$\mathrm{NiNb}$ & 1.36 & 1.83 & -29.47 \\
\hline \hline
\end{tabular}

which shows a positive temperature gradient of surface tension, the other four alloys show almost constant values over the temperature range investigated in this study. The surface tension of a liquid should decrease with rising temperature because at the critical temperature the surface between liquid phase and gas phase disappears and the surface tension is reduced to zero. Negative temperature gradient for surface tension has been found for almost all the pure metals ${ }^{7}$ and the values for two of the constituent elements, $\mathrm{Cu}$ and $\mathrm{Ni}$, are shown in Fig. 1. Positive temperature gradient of surface tension has been reported for another deep-eutectic binary alloy, $\mathrm{Ni}_{36} \mathrm{Zr}_{64} \cdot{ }^{17}$ The anomalous positive temperature gradient of surface tension in some alloys may be due to surface segregation of low surface tension element with increasing undercooling. The temperature dependence of surface tension in $\mathrm{NiNb}$ alloy suggests that there will be considerable amount of Marangoni flow if there are temperature gradients in the sample. However, Marangoni flow will not be significant in the other bulk glass-forming alloys because the surface tension does not change appreciably with temperature, making them suitable for diffusion studies.

The surface tension of most binary liquid mixtures shows negative deviation from the value obtained by assuming rule of mixtures of pure components' surface tension. ${ }^{7}$ This has been attributed to the enrichment of the liquid surface with the component of lower surface tension to minimize the total energy. To evaluate the possible surface segregation effects, the surface tension at the melting (or liquidus) temperatures $\left(\sigma_{m}\right)$ of the alloys investigated in this study are compared with the proportional mathematical addition of pure components' surface tension as shown in Table II. While the three zirconium based alloys (Vit1, Vit106, and $\mathrm{ZrAlCo}$ ) show small deviations from rule of mixtures, $\mathrm{NiNb}$ and NiNbSn show large deviations. The considerably large negative deviation of $52 \%$ in the case of $\mathrm{NiNbSn}$ shows a significant degree of surface segregation of $\mathrm{Sn}$, which has a very low surface tension of $0.56 \mathrm{~N} / \mathrm{m}$. The segregation behavior in binary $\mathrm{Ag}-\mathrm{Sn}$ alloy melts has been investigated theoretically by solving the grand partition functions for the bulk and the surface within the framework of compound formation model. ${ }^{18}$ The theoretical results agree well with the experimental finding for $\mathrm{Ag}-\mathrm{Sn}$ alloys ${ }^{19}$ showing pronounced surface segregation of Sn atoms for all bulk concentrations between 0 and $100 \%$ Sn. The low surface tension values for NiNbSn observed in this study supports this surface segregation behavior of Sn. The total error involved in the surface tension value is estimated to be within $\pm 5 \%$, and the deviations observed for the zirconium-based alloys are

(1) AIP license or copyright, see http://apl.aip.org/apl/copyright.jsp 


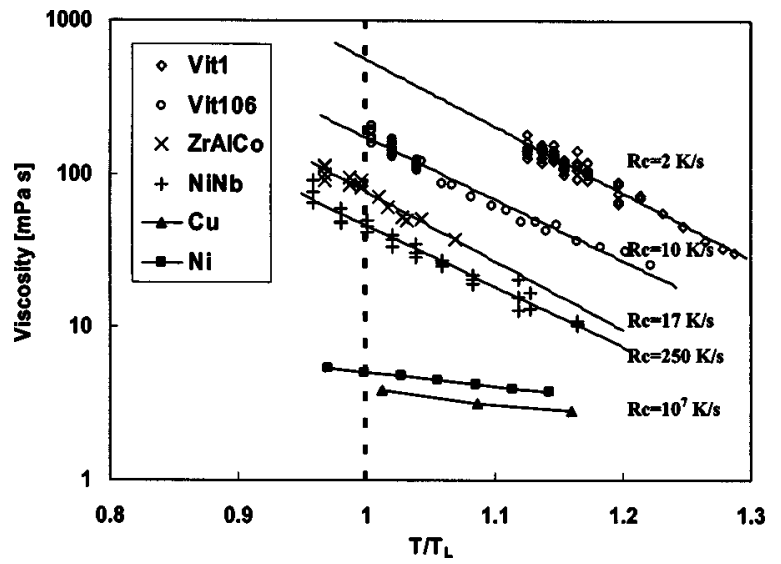

FIG. 2. Viscosity for the alloys investigated in this study with temperature axis normalized by the liquidus temperature $\left(T_{L}\right)$. Viscosity for the pure metals $\mathrm{Ni}$ and $\mathrm{Cu}$ (obtained from Reference 20) is also indicated. The critical cooling rates for vitrification $\left(R_{c}\right)$ are indicated alongside the viscosity data.

Viscosity is a very important parameter in determining the propensity for glass formation and carries special significance for the systems investigated in this study. The viscosities measured for the alloys are shown in Fig. 2 with the temperature axis normalized by their liquidus temperatures $\left(T_{L}\right)$. The viscosities for two of the constituent pure metals, $\mathrm{Cu}$ and $\mathrm{Ni}$, are also shown for comparison. ${ }^{20}$ The viscosities of the ternary NiNbSn alloy are almost in the same range as those of $\mathrm{NiNb}$ and are not indicated. The bulk glass-forming alloys show an order to two orders of magnitude higher viscosity compared to pure metals. Among the bulk glassforming alloys, the better glass former shows higher viscosity. The critical cooling rates $\left(R_{c}\right)$ are indicated alongside the viscosities in Fig. 2. Thus, this study demonstrates that the high viscosity of bulk glass-forming melts plays a decisive role in determining their superior glass-forming ability. Noise level of the measured viscosity is larger at lower temperature because of the increased resistance to oscillation. The maximum viscosity measured was about $200 \mathrm{mPa}$ s. The average error in viscosity measurement from the decay times at the low temperature end is estimated to be within $\pm 5 \%$. For Vit1, the high-temperature viscosities were measured earlier by Masuhr et $a l^{21}$ using a Couette viscometer. The viscosities measured in this study are lower by a factor of 2 compared to Masuhr et $a l_{.}{ }^{21}$ in the region of temperature overlap, $1.12 T_{L}<T<1.17 T_{L}$. The reasons for the discrepancy are being investigated.

Based on hard sphere model, a relationship between surface tension $(\sigma)$ and viscosity $(\eta)$ was derived for pure metals making use of the fact that both surface tension and viscosity can be expressed as integrals over the product of interatomic forces and the pair distribution function: ${ }^{20,22,23}$

$$
\frac{\sigma}{\eta}=\frac{15}{16} \sqrt{\frac{k T}{m}}
$$

where $m$ is the molecular weight, $k$ is the Boltzmann's constant, and $T$ is the temperature. Figure 3 shows $(\sigma / \eta)$ $\times\left(m / T_{L}\right)^{1 / 2}$ plotted versus the square root of temperature normalized by the liquidus temperature $\left(T_{L}\right)$. The correlation has been found to be true for a number of transition and noble metals within 10\%-20\% (shown for $\mathrm{Ni}$ and $\mathrm{Cu}$ in Fig. $3){ }^{20}$ However, for the complex multicomponent alloys, the

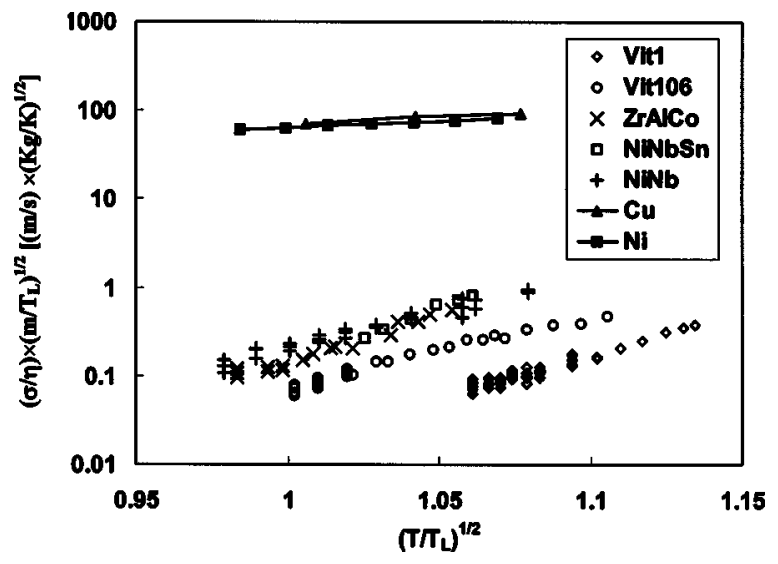

FIG. 3. Correlation between surface tension and viscosity based on hardsphere model for pure metals shows disparity by orders of magnitude in the case of glass-forming alloys.

disparity is by orders of magnitude as shown in Fig. 3. Equation (3) has been derived for pure metals with atoms of a single species and does not take into account the surface segregation and alloying effects which are very important for multicomponent systems. In the case of alloys, this approach may be thought of as an effective medium approximation. However, this study shows that such an approximation fails to explain the experimental results. Thus, Eq. (3) is not suitable to estimate viscosity from surface tension and vice-versa for alloys, as has been done in earlier publications. ${ }^{8}$

This work was carried out at California Institute of Technology under a contract with the National Aeronautical and Space Administration (Grant No. NNMO4AA21G).

${ }^{1}$ A. Inoue, T. Zhang, and T. Masumoto, Mater. Trans., JIM 31, 177 (1990).

${ }^{2}$ A. Peker and W. L. Johnson, Appl. Phys. Lett. 63, 2342 (1993).

${ }^{3}$ Z. P. Lu, C. T. Liu, J. R. Thompson, and W. D. Porter, Phys. Rev. Lett. 92, 245503 (2004).

${ }^{4}$ V. Ponnambalam, S. J. Poon, and G. J. Shiflet, J. Mater. Res. 19, 1320 (2004).

${ }^{5}$ W. L. Johnson, MRS Bull. 10, 42 (1999)

${ }^{6}$ X. J. Han and B. Wei, Philos. Mag. 83, 1511 (2003).

${ }^{7}$ T. Iida and R. I. L. Guthrie, The Physical Properties of Liquid Metals (Clarendon, Oxford, 1988).

${ }^{8}$ H. P. Wang, C. D. Cao, and B. Wei, Appl. Phys. Lett. 84, 4062 (2004).

${ }^{9}$ S. Mukherjee, Z. Zhou, J. Schroers, W. L. Johnson, and W.-K. Rhim, Appl. Phys. Lett. 84, 5010 (2004).

${ }^{10}$ S. Mukherjee, H.-G. Kang, W. L. Johnson, and W.-K. Rhim, Phys. Rev. B 70, 174205 (2004).

${ }^{11}$ X. H. Lin and W. L. Johnson, J. Appl. Phys. 78, 6514 (1995).

${ }^{12}$ S. Mukherjee, Z. Zhou, W. L. Johnson, and W.-K. Rhim, J. Non-Cryst. Solids 337, 21 (2004)

${ }^{13}$ W.-K. Rhim, K. Ohsaka, P.-F. Paradis, and R. E. Spjut, Rev. Sci. Instrum. 70, 2796 (1999)

${ }^{14}$ J. W. S. Rayleigh, Philos. Mag. 14, 184 (1882).

${ }^{15} \mathrm{H}$. Lamb, Hydrodynamics, 6th ed. (Cambridge University Press, Cambridge, 1932), p. 473.

${ }^{16}$ W. K. Rhim, S. K. Chung, D. Barber, K. F. Man, G. Gutt, A. Rulison, and R. E. Spjut, Rev. Sci. Instrum. 64, 2961 (1993).

${ }^{17}$ I. Egry, G. Lohofer, E. Gorges, and G. Jacobs, J. Phys.: Condens. Matter 8, 9363 (1996).

${ }^{18}$ L. C. Prasad, R. N. Singh, V. N. Singh, and G. P. Singh, J. Phys. Chem. B 102, 921 (1998).

${ }^{19}$ J. Lauermann, G. Metzger, and F. Z. Sauerwal, Z. Phys. Chem. (Leipzig) 216, 42 (1961).

${ }^{20}$ I. Egry, Scr. Metall. Mater. 28, 1273 (1993).

${ }^{21}$ A. Masuhr, T. A. Waniuk, R. Busch, and W. L. Johnson, Phys. Rev. Lett. 82, 2290 (1999).

${ }^{22}$ M. Shimoji, Adv. Phys. 16, 705 (1967).

${ }^{23}$ E. T. Turkdogan, Physical Chemistry of High Temperature Technology (Academic, New York, 1980).

Downloaded 14 Dec 2005 to 131.215.225.171. Redistribution subject to AIP license or copyright, see http://apl.aip.org/apl/copyright.jsp 